\title{
Influence of Cooling Rate on the Failure Mechanisms of Protective Oxide Layers on Ni-Based Alloys After the High-Temperature Oxidation
}

\author{
Nadezda V. Sukhodoeva*a, \\ Vladimir V. Moskvichev ${ }^{a, b}$ and Elena N. Fedorova ${ }^{a, b}$ \\ ${ }^{a}$ Siberian Federal University \\ 79 Svobodny, Krasnoyarsk, 660049, Russia \\ 'SKTB "Nauka" ICT SB RAS \\ 53 Mira, Krasnoyarsk, 660049, Russia
}

Received 21.06.2017, received in revised form 24.07.2017, accepted 19.10.2017

A comparative analysis of the microstructure of protective oxide layers formed during high temperature isothermal oxidation $\left(T=1000{ }^{\circ} \mathrm{C}, 50 \mathrm{~h}\right)$ of commercial Ni-based single crystal alloys was carried out. The effect of cooling rate on the integrity of the metal/oxide interface and the damage behavior of oxide layers was established.

Keywords: Ni-based alloys, high temperature isothermal oxidation, cooling rate, oxide scale, failure mechanisms.

Citation: Sukhodoeva N.V., Moskvichev V.V., Fedorova E.N. Influence of cooling rate on the failure mechanisms of protective oxide layers on ni-based alloys after the high-temperature oxidation, J. Sib. Fed. Univ. Eng. technol., 2017, 10(7), 952-960. DOI: 10.17516/1999-494X-2017-10-7-952-960.

(C) Siberian Federal University. All rights reserved

* Corresponding author E-mail address: suhodoevanadezda@gmail.com 


\title{
Влияние скорости охлаждения
}

\section{на механизмы разрушения защитных оксидных слоев \\ на поверхности жаропрочных никелевых сплавов \\ после высокотемпературного окисления}

\author{
Н.В. Суходоева ${ }^{\mathrm{a}}$, В.В. Москвичев ${ }^{\mathrm{a}, \overline{0}}$, Е.Н. Федорова ${ }^{\mathrm{a}, \boldsymbol{0}}$ \\ ${ }^{a}$ Сибирский федеральный университет \\ Россия, 660041, Красноярск, пр. Свободный, 79 \\ ${ }^{6}$ СКТБ «Наука» Института вычислительных технологий СО РАН \\ Россия, 660049, Красноярск, пр. Мира, 53
}

Проведен сравнительный анализ микроструктуры оксидных слоев, формирующихся при высокотемпературном изотермическом окислении ( $T=1000{ }^{\circ} \mathrm{C}, 50$ ч) на поверхности промышленных монокристаллических сплавов на основе никеля. Установлено влияние скорости охлаждения на состояние граниџы раздела металл/оксид и механизмы разрушения оксидных слоев.

Ключевые слова: жаропрочные сплавы на основе никеля, высокотемпературное окисление, скорость охлаждения, защитный оксидный слой, механизмы разрушения.

\section{Введение}

Защитный оксидный слой $\mathrm{Al}_{2} \mathrm{O}_{3}$, характеризующийся низкой скоростью роста, является барьером диффузии кислорода и защищает поверхность жаропрочных никелевых сплавов авиационного назначения от деградации при высокотемпературном окислении. Определяющее влияние на прочность адгезии в системах металл/оксид оказывают остаточные термические напряжения, возникающие в оксидном слое из-за различия коэффициентов термического расширения компонентов и достигающие критических значений во время циклов охлаждения. На скорость релаксации термических напряжений оказывает влияние скорость охлаждения от температуры окисления [1, 2], которая также определяет характер сегрегации примесей (сера, карбиды) на границе раздела металл/оксид $[1,3]$.

Экспериментально показано $[1,2]$, что увеличение скорости охлаждения приводит к увеличению термических напряжений, однако нарушений целостности оксидного слоя при этом может не наблюдаться. Высокие скорости охлаждения (более $100{ }^{\circ} \mathrm{C} /$ мин) позволяют избежать сегрегации карбида хрома или серы на границе раздела металл/оксид, которые могут служить причиной снижения прочности адгезии $[2,3]$. Кроме того, установлено, что увеличение скорости охлаждения приводит к уменьшению размера зерен в приповерхностной зоне сплава, что, в свою очередь, является причиной изменения локального напряженно-деформированного состояния на границе раздела металл/оксид [2].

Интенсивный процесс разрушения оксидного слоя экспериментально наблюдали при охлаждении со средними скоростями $10-100{ }^{\circ} \mathrm{C} /$ мин $[1,2,4]$. Появление отслоений связано с изменениями параметров шероховатости границы раздела металл/оксид за счет микроструктурных изменений $[1,4]$. В [2] отмечается, что отслоение вызвано сегрегацией примесей, приводящих к ослаблению прочности адгезии в системе металл/оксид.

$$
-953-
$$


В данной работе проведено исследование влияния скорости охлаждения на состояние границы раздела металл/оксид и механизмы разрушения оксидного слоя, формирующегося на поверхности жаропрочных никелевых сплавов после высокотемпературного окисления.

\section{Материалы и методы исследования}

Экспериментальные исследования проводились в лаборатории электронно-структурных исследований Центра коллективного пользования ИИФиРЭ СФУ (г. Красноярск). В качестве исходных материалов использовались образцы жаропрочных сплавов на основе никеля отечественного и зарубежного производств (табл. 1), применяемые при изготовлении рабочих лопаток ГТД. Образцы в форме дисков диаметром 10-13 мм и толщиной 1,5 мм были нарезаны из цилиндрических прутков с помощью прецизионной пилы Buehler Isomet 5000. Ось дисков ориентирована вдоль кристаллографического направления [001]. Поверхности образцов предварительно шлифовали на бумаге $\mathrm{SiC}$ и полировали алмазной пастой (до 1 мкм) с применением полировальной установки Buehler Vector, затем очищали в ультразвуковой ванне в ацетоне и спирте высокой чистоты. Взвешивание образцов до и после окисления проводилось на весах Mettler Toledo точностью 0,1 мг.

Высокотемпературное изотермическое окисление сплавов в течение 50 ч проходило в муфельной печи DAIHAN WiseTherm FHP на воздухе при температуре $1000{ }^{\circ} \mathrm{C}$ при использовании различных скоростей охлаждения ( $v_{\text {oxл }}=1.5,30,1000^{\circ} \mathrm{C} /$ мин). Скорость нагрева для всех экспериментов составляла $10{ }^{\circ} \mathrm{C} /$ мин.

Первичный визуальный контроль поверхности образцов после высокотемпературного окисления проводили на оптическом микроскопе Nikon Eclipse LV 100. Дальнейшие исследования микроструктуры и морфологии поверхности оксидного слоя осуществляли на сканирующих электронных микроскопах (CЭM) JEOL JSM 6490LV и JSM 7001F с приставкой для энергодисперсионного анализа (ЭДА) Oxford Inca Energy. Рентгенофазовый анализ (РФА) проводился на приборе Bruker D8 ADVANCE при использовании $\mathrm{Cu}_{\text {к } \alpha}$ излучения, шаге сканирования 0,02 , съемки шли в диапазоне углов $\theta$ от 10 до $50^{\circ}$ при фиксированном угле падения луча $\psi=2^{\circ}$.

\section{Результаты и обсуждения}

\section{Медленная скорость охлаждения $v_{\text {охл }}=1.5^{\circ} \mathrm{C} /$ мин}

Поверхность оксидного слоя, формирующегося на сплаве Rene N5 при T=1000 을 в течение 50 ч, характеризуется неоднородной зернистой структурой (рис. 1a), крупные зерна на поверхности шпинели $\mathrm{NiAl}_{2} \mathrm{O}_{4}$ представляют собой оксид никеля (NiO).

Таблица 1. Химический состав исследуемых жаропрочных сплавов $[5,6]$

Table 1. Chemical composition of high-temperature alloys [5, 6]

\begin{tabular}{|l|c|c|c|c|c|c|c|c|c|c|c|}
\hline \multirow{2}{*}{ Сплав } & \multicolumn{10}{|c|}{ Содержание элементов, \% масс. } \\
\cline { 2 - 14 } & $\mathrm{Ni}$ & $\mathrm{Cr}$ & $\mathrm{Co}$ & $\mathrm{Mo}$ & $\mathrm{W}$ & $\mathrm{Al}$ & $\mathrm{Ti}$ & $\mathrm{Ta}$ & $\mathrm{Nb}$ & $\mathrm{Re}$ & $\mathrm{Hf}$ \\
\hline ЖC36, ВИАМ, Россия & осн. & 4.0 & 7.0 & 1.6 & 11.7 & 5.8 & 1.1 & - & 1.1 & 2.0 & - \\
\hline Rene N5, General Electric, США & осн. & 7.0 & 8,0 & 2.0 & 5.7 & 6.2 & - & 7.0 & - & 3.0 & 0.15 \\
\hline
\end{tabular}


В результате исследования поперечных срезов образцов Rene N5 после окисления установлено наличие нескольких слоев: внутреннего (прилегающего к границе раздела металл/оксид) слоя $\alpha-\mathrm{Al}_{2} \mathrm{O}_{3}$, промежуточного слоя шпинели $\mathrm{NiAl}_{2} \mathrm{O}_{4}$ с дискретными включениями оксидов тантала и титана и внешнего слоя - крупные зерна $\mathrm{NiO}$ (рис. 16). Согласно результатам измерений на поперечных срезах методом СЭМ средняя толщина оксидного слоя 5,5 $\pm 0,3$ мкм, толщины перечисленных выше слоев составляют 1,2 мкм $\left(\mathrm{Al}_{2} \mathrm{O}_{3}\right), 1,5$ мкм $\left(\mathrm{NiAl}_{2} \mathrm{O}_{4}\right)$ и 2,8 мкм (NiO) соответственно. На границе раздела верхнего слоя $\mathrm{NiO}$ и слоя $\mathrm{NiAl}_{2} \mathrm{O}_{4}$ обнаружены дефекты, которые могут служить причиной слабой прочности адгезии данной границы раздела.

Для оксидного слоя на поверхности сплава ЖС36 характерна достаточно однородная структура с крупными плотноупакованными зернами, средний размер которых составляет 3-5 мкм (рис. 2a). Поперечный срез оксидного слоя на ЖС36 практически не отличается по микроструктуре от слоя на поверхности сплава Rene N5, однако имеет значительно большую

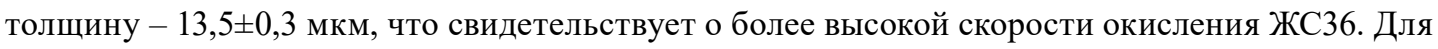
границы раздела $\mathrm{NiO} /$ шпинель также характерно наличие дефектов.

При медленном охлаждении ( $\left.v_{\text {oxл }}=1.5^{\circ} \mathrm{C} / \mathrm{Mин}\right)$ на поверхности исследуемых сплавов дефектов и отслоений оксидного слоя не обнаружено.

\section{Средняя и высокая скорости охлаждения $\left(v_{\text {охл }}=30^{\circ} \mathrm{C} /\right.$ мин и $1000^{\circ} \mathrm{C} /$ мин $)$}

При исследовании поверхности оксидного слоя на образцах сплава Rene N5 методами оптической и сканирующей электронной микроскопии установлено, что увеличение скорости охлаждения приводит к образованию дефектов круглой формы (рис. 3). При этом максимальное количество дефектов, диаметр которых составляет 100-150 мкм, наблюдается после охлаждения со средней скоростью ( $v_{o x л}=30^{\circ} \mathrm{C} /$ мин). Согласно результатам ЭДА характерных зон дефекта установлено, что светлые скопления зерен во внутренних зонах дефектов соответствуют оксиду алюминия $\mathrm{Al}_{2} \mathrm{O}_{3}$, внешняя темная зона - сложный оксид, который, по всей вероятности, имеет структуру шпинели $\mathrm{Ni}(\mathrm{Al}, \mathrm{Cr})_{2} \mathrm{O}_{4}$. Наличие $\mathrm{NiO}$ в зонах дефектов не установлено.
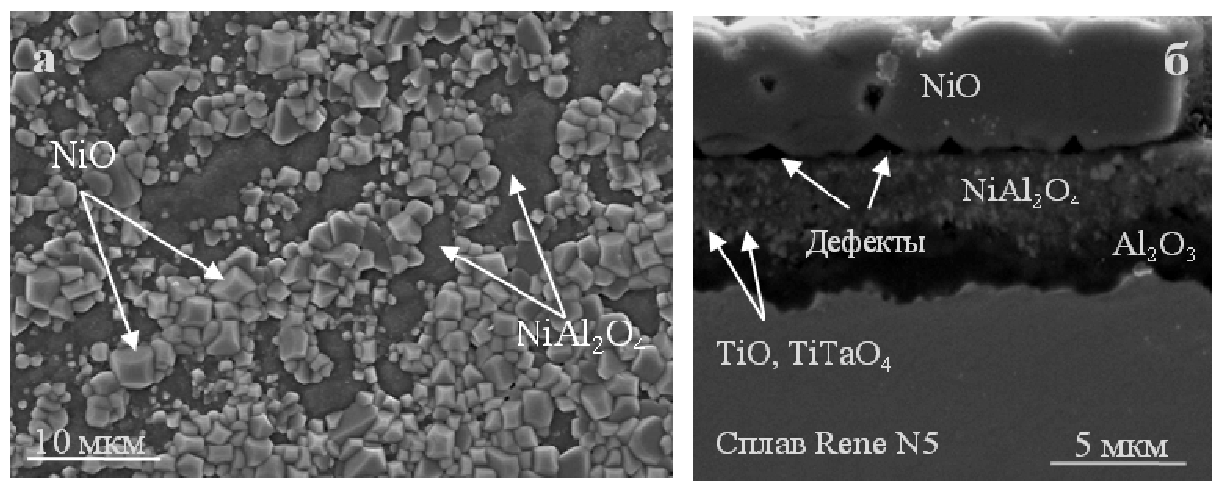

Рис. 1. Поверхность (а) и поперечный срез (б) оксидного слоя на поверхности сплава Rene N5 после изотермического окисления в течение 50 ч при $\mathrm{T}=1000{ }^{\circ} \mathrm{C}\left(v_{o x x}=1.5^{\circ} \mathrm{C} /\right.$ мин $)$; СЭМ

Fig. 1. Surface SEM micrographs (a) and cross-section (b) of the oxide layer on Rene N5 after isothermal oxidation $50 \mathrm{~h}$ at $1000^{\circ} \mathrm{C}\left(\mathrm{v}=1.5^{\circ} \mathrm{C} / \mathrm{min}\right)$ 

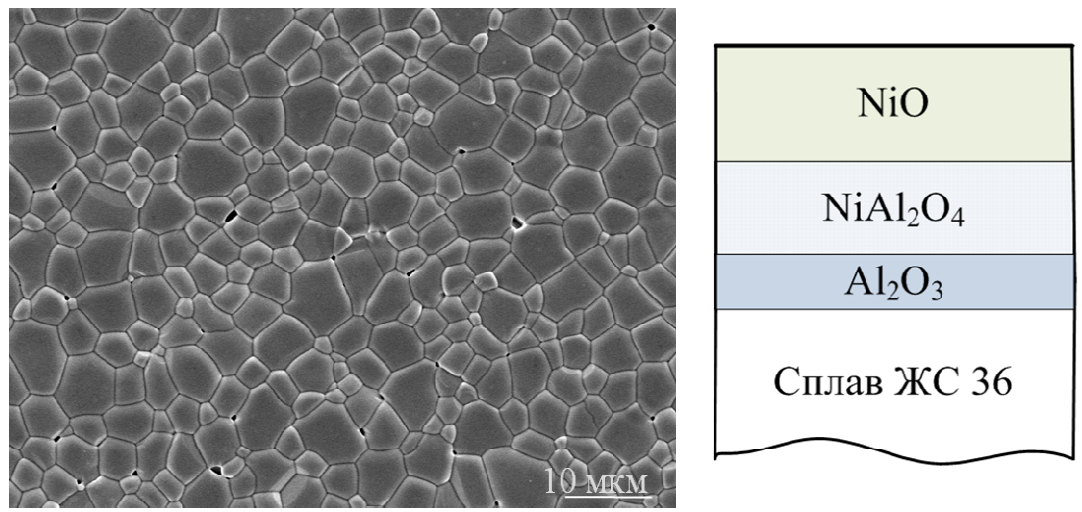

Рис. 2. Поверхность (а) и схематическое представление поперечного среза (б) оксидного слоя на поверхности сплава ЖС 36 после изотермического окисления в течение 50 ч при $\mathrm{T}=1000{ }^{\circ} \mathrm{C}\left(v_{\text {oxл }}=1.5^{\circ} \mathrm{C} /\right.$ мин $)$; СЭМ

Fig. 2. Surface SEM micrographs (a) and schematic representation of the cross-section (b) of the oxide layer on GS36 after isothermal oxidation $50 \mathrm{~h}$ at $1000^{\circ} \mathrm{C}\left(\mathrm{v}=1.5^{\circ} \mathrm{C} / \mathrm{min}\right)$
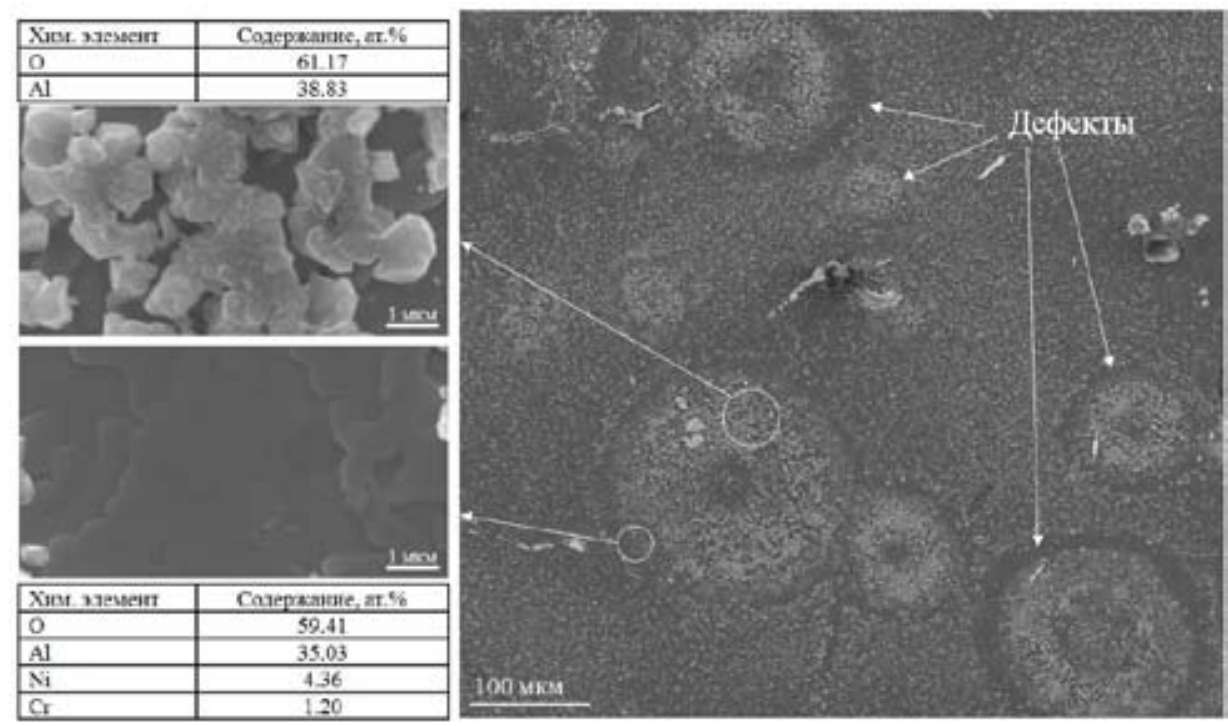

Рис. 3. Дефекты на поверхности сплава Rene N5 после окисления в течение 50 ч при $\mathrm{T}=1000{ }^{\circ} \mathrm{C}$ $\left(v_{\text {oxл }}=30^{\circ} \mathrm{C} /\right.$ мин $) ;$ СЭМ и ЭДА

Fig. 3. SEM micrographs and EDA results of the failure zones on Rene N5 after oxidation $50 \mathrm{~h}$ at $1000{ }^{\circ} \mathrm{C}$ $\left(\mathrm{v}=30^{\circ} \mathrm{C} / \mathrm{min}\right)$

При исследовании поперечных срезов сплава Rene N5 после окисления в течение 50 ч при $\mathrm{T}=1000{ }^{\circ} \mathrm{C}$ установлено, что увеличение скорости охлаждения от 1,5 до $1000{ }^{\circ} \mathrm{C} /$ мин не приводит к существенным изменениям состояния границ раздела и целостности оксидного слоя за исключением отслоений $\mathrm{NiO}$ в зонах, соответствующих дефектам, изображенным на рис. 3.

По сравнению со сплавом Rene N5 на поверхности оксидного слоя на сплаве ЖС36 при увеличении скорости охлаждения дефектов не наблюдается. Однако при исследовании попе-

$$
-956-
$$


речных срезов установлено, что при увеличении скорости охлаждения происходит смена механизма разрушения. При медленном охлаждении ( $\left.v_{\text {oxл }}=1,5^{\circ} \mathrm{C} / \mathrm{мин}\right)$ дефекты присутствуют на верхней границе раздела (между слоями $\mathrm{NiO}$ и $\mathrm{NiAl}_{2} \mathrm{O}_{4}$ ) (рис. $4 a$ ), при охлаждении со скоростями $v_{\text {охл }}=30{ }^{\circ} \mathrm{C} /$ мин и $v_{\text {охл }}=1000^{\circ} \mathrm{C} /$ мин разрушение инициируется путем зарождения трещин на нижней границе раздела (между слоями $\mathrm{NiAl}_{2} \mathrm{O}_{4}$ и $\mathrm{Al}_{2} \mathrm{O}_{3}$ ) и в слое $\mathrm{Al}_{2} \mathrm{O}_{3}$ (рис. 4б).

Результаты проведенных исследований показывают, что при изменении режимов охлаждения образующиеся дефекты могут привести к отслоению и последующему разрушению оксидного слоя. В этой связи были проведены дополнительные эксперименты при высокой скорости охлаждения $\left(v_{\text {oxл }}=1000^{\circ} \mathrm{C} /\right.$ мин) и при различных $\Delta T$, (где $\Delta T$ - это изменение температуры от температуры окисления до комнатной).

Для сплава Rene N5 установлено критическое значение $\Delta \mathrm{T}=880{ }^{\circ} \mathrm{C}$, при котором происходит зарождение трещин по верхней границе раздела (между слоями $\mathrm{NiAl}_{2} \mathrm{O}_{4}$ и $\mathrm{NiO}$ ), которые затем приводят к поднятию (вздутию) верхнего слоя $\mathrm{NiO}$ (рис. 5).

Модель отслоения, согласно которой разрушение оксидного слоя начинается с образования трещин, инициируемых дефектами границы раздела металл/оксид, в литературе известна
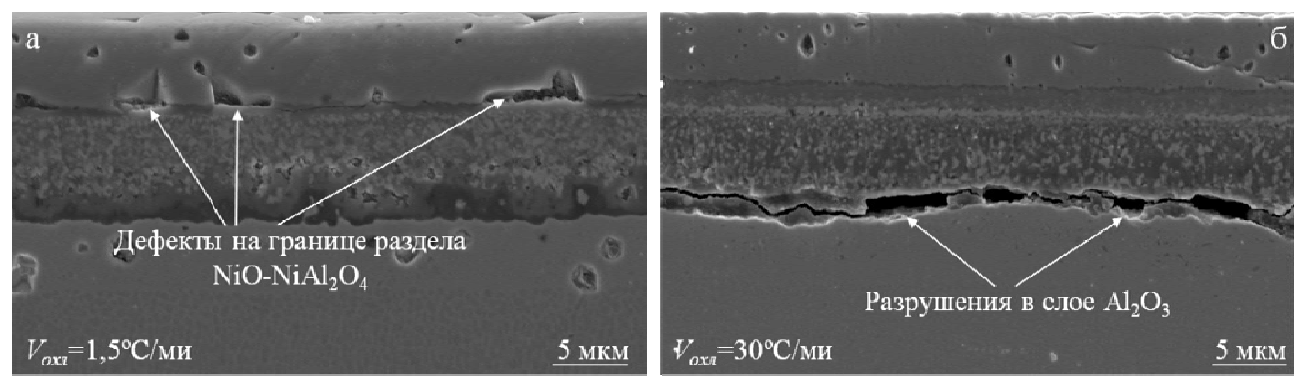

Рис. 4. Смена механизма разрушения в оксидном слое на поверхности сплава ЖС36 после изотермического окисления в течение 50 ч при $\mathrm{T}=1000^{\circ} \mathrm{C}$ и охлаждения с разными скоростями $v_{\text {oxл }}=1,5^{\circ} \mathrm{C} /$ мин (а) и $v_{\text {oxл }}=30^{\circ} \mathrm{C} /$ мин (б); СЭМ

Fig. 4. Change of the failure mechanism on GS36 after isothermal oxidation $50 \mathrm{~h}$ at $1000{ }^{\circ} \mathrm{C}$ with different cooling rates $\mathrm{v}=1.5^{\circ} \mathrm{C} / \mathrm{min}(\mathrm{a})$ and $\mathrm{v}=30^{\circ} \mathrm{C} / \mathrm{min}(\mathrm{b})$

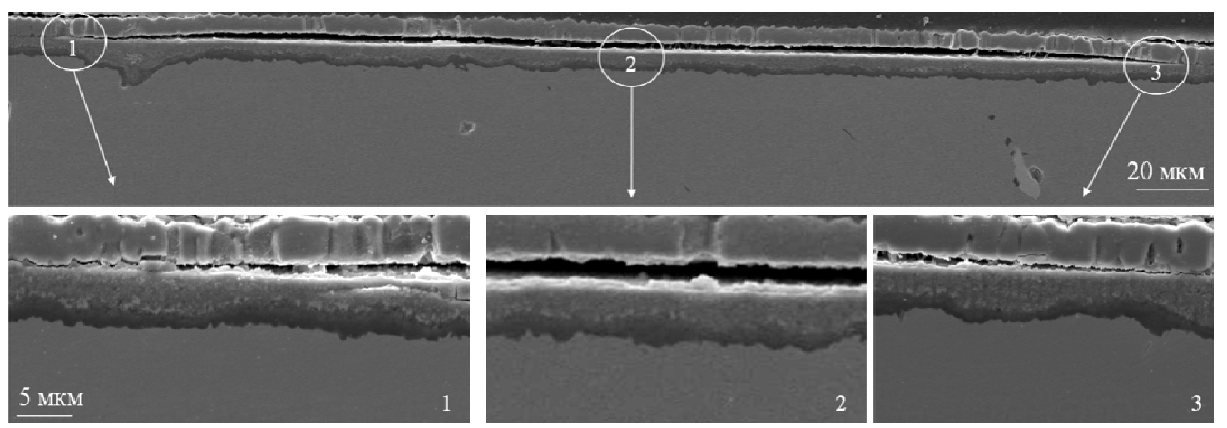

Рис. 5. Разрушение оксидного слоя по границе раздела $\mathrm{NiAl}_{2} \mathrm{O}_{4}$ и $\mathrm{NiO}$ на поверхности сплава Rene $\mathrm{N} 5$ после изотермического окисления в течение 50 ч при $\mathrm{T}=1000{ }^{\circ} \mathrm{C}\left(\mathrm{v}_{\text {охл }}=1000{ }^{\circ} \mathrm{C} / \mathrm{Mин}, \Delta \mathrm{T}=880{ }^{\circ} \mathrm{C}\right)$

Fig. 5. SEM cross-section of $\mathrm{NiAl}_{2} \mathrm{O}_{4} / \mathrm{NiO}$ interfacial failure on Rene $\mathrm{N} 5$ after isothermal oxidation $50 \mathrm{~h}$ at $1000{ }^{\circ} \mathrm{C}$ $\left(\mathrm{v}=1000^{\circ} \mathrm{C} / \mathrm{min}, \Delta \mathrm{T}=880^{\circ} \mathrm{C}\right)$ 
как «вздутие» (рис. 6a) [7-9]. Разрушение по данному механизму более вероятно для систем с толщиной оксидного слоя, не превышающей 10 мкм. Подобный механизм разрушения оксидного слоя был установлен на поверхности сплава Rene N5 после изотермического окисления в течение 10 ч при $\mathrm{T}=1150{ }^{\circ} \mathrm{C}$ и быстрого охлаждения $v_{\text {охл }}=1000{ }^{\circ} \mathrm{C} /$ мин [10].

Отслоение оксидного слоя достаточно большой толщины (более 10 мкм) может произойти по механизму скалывания (рис. 6б, табл. 2) [8, 9]. Разрушение возникает в результате развития трещин сдвига в оксидном слое, появляющихся при достижении критического уровня остаточных напряжений. При этом граница раздела при данном типе разрушения характеризуется достаточно высокой прочностью адгезии, превышающей прочность самого оксидного слоя.

Ввиду того, что оксидный слой, формирующийся на поверхности монокристаллического сплава ЖС36 во время высокотемпературного окисления, имеет достаточно большую толщину
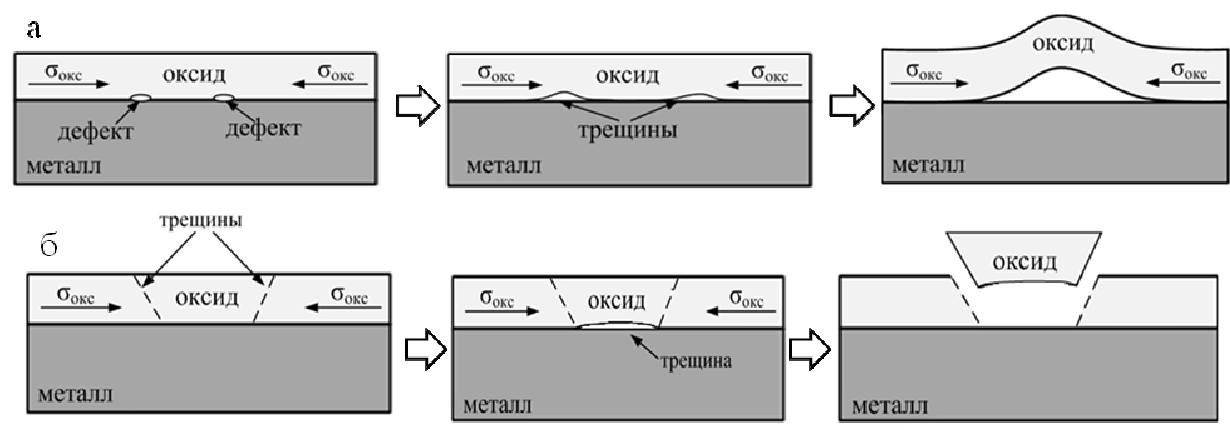

Рис. 6. Механизмы разрушения: а - вздутие; б - скалывание [7-9]

Fig. 6. Failure mechanisms: $a$ - buckling; $b$ - wedging [7-9]

Таблица 2. Механизмы разрушения в различных системах после высокотемпературного окисления, согласно литературным данным

Table 2. Failure mechanisms of various systems after high temperature oxidation

\begin{tabular}{|c|c|c|c|}
\hline $\begin{array}{c}\text { Механизм } \\
\text { разрушения }\end{array}$ & Система/граница раздела & Условия окисления & Источник \\
\hline \multirow{3}{*}{ Скалывание } & $\mathrm{NiAl} / \mathrm{Al}_{2} \mathrm{O}_{3}$ & $\mathrm{t}=20$ ч $\mathrm{T}=1050^{\circ} \mathrm{C}$ & {$[11]$} \\
\hline & Сплав на основе $\mathrm{Fe} / \mathrm{Cr}_{2} \mathrm{O}_{3}$ & $\mathrm{t}=600,900$ ч $\mathrm{T}=800-850^{\circ} \mathrm{C}$ & {$[12]$} \\
\hline & Сплав на основе $\mathrm{Fe} / \mathrm{Cr}_{2} \mathrm{O}_{3}$ & $\mathrm{t}=100$ ч $\mathrm{T}=1000^{\circ} \mathrm{C}$ & {$[13]$} \\
\hline \multirow{4}{*}{ Вздутие } & \multirow{3}{*}{ Сплав на основе $\mathrm{Fe} / \mathrm{Al}_{2} \mathrm{O}_{3}$} & $\begin{array}{c}\mathrm{t}=0.5-100 \text { ч } \mathrm{T}=1200{ }^{\circ} \mathrm{C} \\
\mathrm{v}=2-1000{ }^{\circ} \mathrm{C} / \text { мин }\end{array}$ & {$[1]$} \\
\hline & & $\begin{array}{l}\mathrm{t}=25 \text { ч } \mathrm{T}=1200^{\circ} \mathrm{C} \\
v=2-100^{\circ} \mathrm{C} / \mathrm{мин}\end{array}$ & {$[4]$} \\
\hline & & $\mathrm{t}=100$ ч $\mathrm{T}=1200^{\circ} \mathrm{C}$ & {$[14]$} \\
\hline & Сплав на основе $\mathrm{Ni} / \mathrm{Al}_{2} \mathrm{O}_{3}$ & $\begin{array}{l}\mathrm{t}=10 \text { ч } \mathrm{T}=1150{ }^{\circ} \mathrm{C} \\
\mathrm{v}=10-100^{\circ} \mathrm{C} / \text { мин }\end{array}$ & {$[10]$} \\
\hline \multirow{2}{*}{$\begin{array}{c}\text { Вздутие и } \\
\text { скалывание }\end{array}$} & Сплав на основе $\mathrm{Fe} / \mathrm{Cr}_{2} \mathrm{O}_{3}$ & $\mathrm{t}=$ до 1000 ч $\mathrm{T}=850^{\circ} \mathrm{C}$ & {$[8]$} \\
\hline & Сплав на основе $\mathrm{Fe} / \mathrm{Al}_{2} \mathrm{O}_{3}$ & $\mathrm{t}=1400$ ч $\mathrm{T}=1150-1300^{\circ} \mathrm{C}$ & {$[15]$} \\
\hline
\end{tabular}




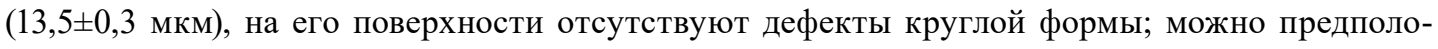
жить, что увеличение толщины оксидного слоя (следовательно, увеличение остаточных напряжений) может привести к отслоению по механизму скалывания.

\section{Заключение}

В работе исследовано влияние скорости охлаждения на состояние границы раздела металл/оксид и механизмы разрушения оксидного слоя, формирующегося на поверхности жаропрочных монокристаллических никелевых сплавов после высокотемпературного изотермического окисления.

Показано, что при увеличении скорости охлаждения для оксидного слоя на поверхности сплава Rene N5 характерно зарождение дефектов круглой формы, которые при увеличении $\Delta T$ (следовательно увеличении остаточных напряжений) приводят к отслоению по механизму вздутия. Для оксидного слоя на сплаве ЖС36 наблюдается смена механизма разрушения. При медленном охлаждении происходит формирование дефектов на верхней границе раздела $\mathrm{NiO} / \mathrm{NiAl}_{2} \mathrm{O}_{4}$, при увеличении скорости охлаждения - трещины возникают на нижней границе раздела (между слоями $\mathrm{NiAl}_{2} \mathrm{O}_{4}$ и) и в слое $\mathrm{Al}_{2} \mathrm{O}_{3}$. Разрушение оксидного слоя возможно путем отслоения по механизму скалывания при увеличении его толщины, которое сопровождается ростом остаточных напряжений.

Авторы выражают благодарность к.т.н., доценту кафедры МиТОМ ПИ СФУ Г.М. Зеер за помощь в проведении энергодисперсионного анализа образцов.

\section{Список литературы}

[1] Tolpygo V.K., Clarke D.R. Spalling failure of a-alumina films grown by oxidation: I. Dependence on cooling rate and metal thickness. Materials Science and Engineering, 2000, A278, $142-150$.

[2] Zhu C., Zhao X., Molchan I.S., Thompson G.E., Liang G., Xiao P. Effect of cooling rate and substrate thickness on spallation of alumina scale on Fecralloy. Materials Science and Engineering A, 2011, Vol. 528, 8687-8693.

[3] Hou P.Y. Segregation phenomena at thermally grown $\mathrm{Al}_{2} \mathrm{O}_{3} /$ alloy interfaces. Annu Rev Mater Res 2008, 38, 275-298.

[4] Tolpygo V.K., Clarke D.R. Spalling failure of a-alumina films grown by oxidation. II. Decohesion nucleation and growth. Materials Science and Engineering, 2000, A278, 151-161.

[5] Каблов Е.Н. Литые лопатки газотурбинных двигателей: сплавы, технологии, покрытия. М.: Наука, 2006, 632 с. [Kablov E.N. Cast blades of gas turbine engines: alloys, technologies, coatings, Moscow: Nauka, 2006, 632 p. (in Russian)]

[6] Patent 0076360 US C22C1/02, C22C19/05, C22F1/10. Single crystal nickel-base superalloy, articles and method for making; Wukusick C.S., Buchakjian Jr.L.; Gen Electric. - EP19820104705; 28.05.1982, 16.05.1984. P. 30.

[7] Evans U.R. An introduction to metallic corrosion. Edward Arnold, 1948, 194-195.

[8] Evans H.E., Lobb R.C. Conditions for the initiation of oxide-scale cracking and spallation. Corrosion Science, 1984, Vol. 24 (3), 209-224.

$$
-959-
$$


[9] Evans H.E. Stress effects in high temperature oxidation of metals. International Materials Reviews, 1995, Vol. 40(1), 40.

[10] Москвичев В.В., Суходоева Н.В., Федорова Е.Н., Попов А.С. Оценка энергии адгезии в системе металл/оксид для случая высокотемпературного окисления жаропрочных никелевых сплавов. Деформация и разрушение материалов, 2017, 2, 34-40. [Moskvichev V.V., Sukhodoeva N.V., Fedorova E.N. Quantification of metal/oxide adhesion energie after higt temperature oxidation of Ni-based alloy, Deformatsiya i Razrushenie materialov, 2017, 2, 34-40 (in Russian)]

[11] Maurel et al. The respective roles of thermally grown oxide roughness and NiAl coating anisotropy in oxide spallation. Surface \& Coatings Technology, 2013, 215, 52-61.

[12] Liu W.N. et al. Effect of substrate thickness on oxide scale spallation for solid oxide fuel cells. Corrosion Science, 2011, 53, 2406-2412.

[13] Hayashi A., Hiraide N., Inoue Y. Spallation Behavior of Oxide Scale on Stainless Steels. Oxid Met, 2016, 85, 87-101.

[14] Pint B.A., Tortorelli P.F., Wright I.G. The oxidation behavior of ODS iron aluminides. Materials and Corrosion, 1996, 47, 663-674.

[15] Bull S.J., Berasetegui E.G. An overview of the potential of quantitative coating adhesion measurement by scratch testing. Tribology International, 2006, 39, 99-114. 